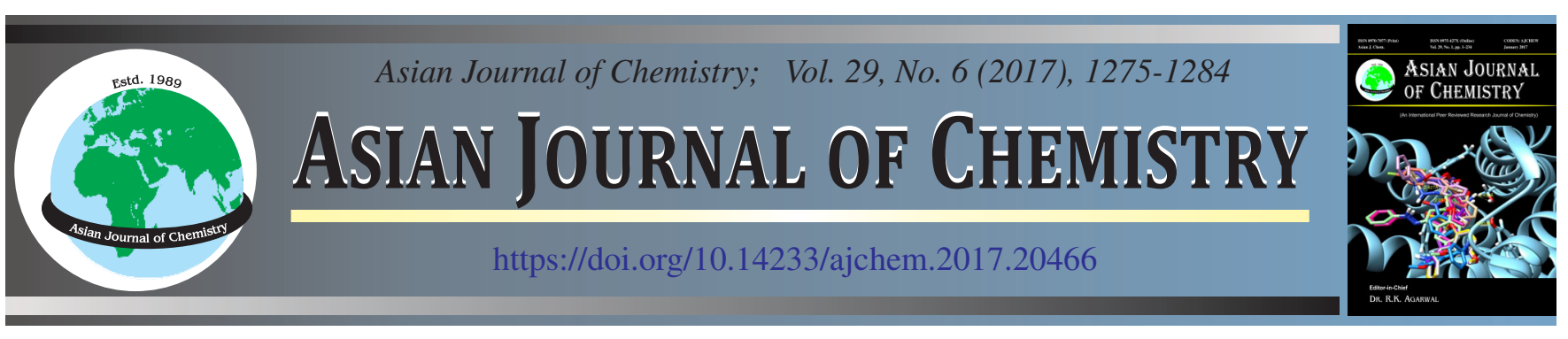

\title{
Buoyant in situ Gels of Meloxicam- $\beta$-Cyclodextrin-Triethanolamine Ternary Complex for Oral Delivery; From a Box-Behnken Experimental Design to in vivo Activity Detail
}

\author{
Mohammed Jafar ${ }^{1, *}$, Mohammed SALAhUddin ${ }^{2}$, TAReK S. KAYed ${ }^{3}$, NiYaz Ahmad ${ }^{1}$, \\ Huda A. Al-Eid ${ }^{1}$ and Abdullah H. Al-QARros ${ }^{1}$
}

\begin{abstract}
${ }^{1}$ Department of Pharmaceutics, College of Clinical Pharmacy, University of Dammam, P.O. Box 1982, Dammam-31441, Saudi Arabia ${ }^{2}$ Institute for Research and Medical Consultation studies, University of Dammam, P.O. Box 1982, Dammam-31441, Saudi Arabia

${ }^{3}$ Department of Basic Sciences and Humanities, College of Engineering, University of Dammam, P.O. Box 1982, Dammam-31441, Saudi Arabia
\end{abstract}

*Corresponding author: Tel: +966 502467326; E-mail: mjomar@uod.edu.sa

The aim of the present study was to ameliorate the aqueous solubility and dissolution rate of meloxicam by preparing its ternary complex with $\beta$-cyclodextrin and triethanolamine and to develop its gastric buoyant in situ gels to improve in vivo anti-inflammatory activity of meloxicam. Meloxicam- $\beta$-cyclodextrin-triethanolamine ternary complexes were characterized by FTIR, XRD and SEM techniques. A total of fifteen meloxicam- $\beta$-cyclodextrin-triethanolamine ternary complex incorporated buoyant in situ gels were prepared and optimized using a Box-Behnken design. Independent variables (concentrations of gellan gum, calcium carbonate and meloxicam respectively) were optimized in order to achieve the desired responses. The response surface plots and the possible interactions between the independent variables were analyzed using the Design Expert software 10.0.3. (Stat-Ease, Inc, USA). The results showed that the optimized buoyant in situ gels with short floating lag time $(0.7 \mathrm{~min})$, low viscosity $(210 \mathrm{cps})$ and high in vitro drug release at $6^{\text {th }}$ hour $(92 \%)$ was obtained using an optimized combination of calcium carbonate $(0.75 \% \mathrm{w} / \mathrm{v})$, gellan gum $(0.25 \% \mathrm{w} / \mathrm{v})$ and MLX- $\beta$-CD-TEA ternary complex (equivalent to $11 \mathrm{mg}$ of meloxicam), respectively. The optimized formulation exhibited significantly high anti-inflammatory activity compared to in situ gel containing pure meloxicam. It was stable for over 3 months. Hence it may be used for the effective oral delivery of meloxicam.

Keywords: Meloxicam, Inclusion complex, Solubility, in situ gel, in vivo activity.

\section{INTRODUCTION}

Meloxicam, a quite new cyclo-oxygenase inhibitor, belongs to the enolic acids class of NSAIDs. It is approved by FDA for the long-term treatment of osteoarthritis, rheumatoid arthritis, ankyloising spondolytis and so forth. It has a poor aqueous solubility [1] and therefore, on oral administration, it remains as unionized lipophilic form in the highly acidic stomach region. These conditions support the migration into the surface epithelial cells where it is dissociated into an ionized form that traps hydrogen ions, consequently producing highly critical local concentration, which lead to irritation in the stomach wall, stomach pain, rupture of gastric mucosa, gastric bleeding and ulceration [2,3], this risk may become much higher for people who are older in age [4], have poor health, or consume a large quantity of alcohol [5]. Moreover, the poor solubility and slow dissolution rate of the lipophilic drugs in the gastrointestinal fluid, besides posing difficulties in the manufacture of pharmaceutical preparations such as liquid orals, may also give rise to fluctuating oral bioavailability and poor therapeutic response of the drug [6].
Cyclodextrins (CDs) a structurally interrelated oligosaccharides with six $(\alpha-C D)$, seven $(\beta-C D)$ and eight $(\gamma-C D) \alpha-1,4-$ glucopyranose units, play a vital role in improving therapeutic efficacy of drug molecules with poor solubility [7]. They are capable of assuaging the undesirable characteristics of drugs through the formation of inclusion complexes. Among the various cyclodextrins, $\beta$-cyclodextrin has been the most commonly used inclusion compound owing to its vast availability, low cost, absolute biocompatibility and also wide regulative acceptance [8]. Moreover, recent report evidenced that pre-associating NSAIDs with $\beta$-CD could save rats against the damaging GI adverse effects of NSAIDs while enhancing their bioactivity [9]. Nevertheless, the poor water solubility of $\beta-C D$ is a major hurdle in its vast application.

A surge of scientific studies in this area revealed that the incorporation of a small amount of suitable auxiliary materials like hydrophilic polymers, organic acids, amino acids and hydroxyl organic amines, to a drug- $\beta$-CD complex could ameliorate both the complexation and solubilizing potentialities of the $\beta-\mathrm{CD}$ and ultimately reduce its amount in pharmaceutical 
formulations. Such outcomes are ascribed to the complementary effect of added substance and $\beta-C D$ on the formation of ternary complexes. Triethanolamine (TEA) evidently has been successfully employed with the aim to enhance the effectiveness of drug delivery and boost the cyclodextrin solubilizing potential towards acidic drugs such as methotrexate [10], gemfibrozil [11], flurbiprofen [12], ketoprofen and chlorthiazide [13]. Regarding its oral application, TEA could favourably improve in rats the per-oral absorption/bioavailability of piroxicam [14] and meloxicam [15] via salt formation.

Oral solutions offer several advantages over other oral pharmaceutical formulations such as emulsions, suspensions, tablets and capsules, but they often suffer from abrupt gastrointestinal transit. This could be a serious concern for the majority of drugs, particularly weakly acidic drugs as they are absorbed from the stomach and/or upper part of the small intestine $[16,17]$. The gastric retention of oral solutions containing these drugs could be favourably achieved through a radical approach of liquid in situ gelling system. These systems are polymeric gel formulations respond to physical or chemical signals, including $\mathrm{pH}$, ionic factor, metabolite or temperature [18-20]. Numerous polymers such as pectin, chitosan, gellan gum, xyloglucan and xanthan gum have been investigated for this purpose. Gellan gum is a bacterial anionic deacetylated polysaccharide produced by Pseudomonas elodea. It undergoes gel formation by virtue of temperature change or because of the presence of cations $\left(\right.$ e.g. $\left.\mathrm{Na}^{+}, \mathrm{K}^{+}, \mathrm{Ca}^{2+}\right)$. It is a water soluble polysaccharide. It produces a gel via formation of double helices, followed by their ionic cross linking. Incorporation of suitable amounts of gas forming substance like calcium carbonate, to the aqueous solutions of the above polymers could make them float on the surface of the gastric fluid [21]. This floating property of the gels could help in minimizing the gastric irritant effect of weakly acidic drugs by preventing direct contact with the stomach mucosa [22].

Over the years, substantial work mainly related to the solubility enhancement of meloxicam with the use of hydrophilic excipients alone [23-25] or in combination with cyclodextrins $[26,27]$ has been reported and also there some reports appeared in the literature about the meloxicam-cyclodextrin and/or hydrophilic excipient complex/dispersion incorporated formulations such as tablets [28], suspension [29], suppositories [30] and buccal patches [31]. However, there is a lack of evidence in the literature about the meloxicam ternary complex (prepared using cylodextrins and alkali substance combination) incorporated gastric bouyant in situ gels, even though this has been considered to be very beneficial from the pharmaceutical and therapeutic point of view.

Therefore the present study was planned to achieve the following objectives: 1) To improve the aqueous solubility and in vitro dissolution rate of poorly soluble meloxicam by preparing its ternary complexes with $\beta$-cyclodextrin and triethanolamine and characterize them by spectral, diffractometric and microscopic techniques and 2) To develop gastric buoyant in situ gels by incorporating selected ternary complex of meloxicam to improve its in vivo anti-inflammatory activity. Box-Behnken design [32], which gives small number of experimental runs and takes less time and thus offers a far more effective approach than the traditional approaches con-cerning statistical optimization of a pharmaceutical formulation [33] is used in the design of buoyant in situ gels of meloxicam- $\beta$ cyclodextrin-triethanolamine ternary complex.

\section{EXPERIMENTAL}

Meloxicam is purchased from the UFC Biotechnology New York (USA), $\beta$-Cyclodextrin, triethanolamine, gellan gum and calcium carbonate were purchased from the Research lab fine chemicals Mumbai (India), while other ingredients used were of analytical research grade.

Phase solubility studies: Solubility determinations of meloxicam were conducted as per the reported method [34]. An excess amount of meloxicam $(50 \mathrm{mg}$ ) was added to $20 \mathrm{~mL}$ aqueous $\beta$-cyclodextrin solutions of increasing concentration ( 3 to $15 \mathrm{mM}$ ) in $50 \mathrm{~mL}$ stoppard conical flasks. After shaking the contents of the flask at $37{ }^{\circ} \mathrm{C}$ for $72 \mathrm{~h}$ on a mechanical shaker, the undissolved meloxicam was filtered through a 0.45 mm filter paper (Whatman Grade 2589a) and the solutions after appropriate dilutions were assayed for meloxicam content at $362 \mathrm{~nm}$ spectrophotometrically. Phase solubility studies of meloxicam were also performed with the incorporation of triethanolamine at a concentration of $0.5 \% \mathrm{w} / \mathrm{v}$ to the solutions containing $\beta$-cyclodextrin. The blank experiments were run simultaneously in the same concentrations of $\beta$-cyclodextrin in distilled water in order to cancel out any absorbance if showed by $\beta$-cyclodextrin molecules. The above solubility experiments were repeated for two more times to get accuracy in the results. The apparent stability constants $\left(\mathrm{K}_{1: 1}\right)$ were computed from phase solubility diagrams using the below equation:

$$
\mathrm{K}_{1: 1}=\frac{\text { Slope }}{\mathrm{S}_{\mathrm{o}}(1-\text { Slope })}
$$

where $S_{o}$ is the intrinsic solubility of pure meloxicam.

Preparation of solid complexes: Meloxicam- $\beta$-cyclodextrin-triethanolamine (MLX- $\beta$-CD-TEA) ternary complexes at $1: 1: 0.5,1: 1: 1$ and 1:1:1.5 molar ratios respectively, were prepared by the solvent evaporation method [35] as follows: Calculated amounts of meloxicam, $\beta$-cyclodextrin and triethanolamine were dissolved in a small quantity of dimethyl formamide in a beaker and stirred at $600 \mathrm{rpm}$ for $1 \mathrm{~h}$ to attain equilibrium. The solvent was removed using a rotary evaporator (IKA, Germany) under reduced pressure at room temperature. MLX- $\beta$-CD-TEA ternary complexes thus obtained were dried in vacuum at room temperature for $12 \mathrm{~h}$. The dried mass was pulverized and sieved through a 60-mesh screen and stored in desiccators until used for further investigation. A batch of meloxicam- $\beta$-cyclodextrin (1:1 molar ratio) binary complex and also physical mixtures in equal ratios to the ternary complexes were prepared as the references for the characterization.

\section{Characterization of raw materials and solid complexes of meloxicam}

Fourier transformed infrared spectroscopy: FTIR spectra of MLX, $\beta$-CD, TEA, MLX- $\beta$-CD binary complex, MLX- $\beta$-CD-TEA ternary complexes and physical mixtures of MLX- $\beta$-CD-TEA were measured as potassium bromide 
discs on Nicolet iS 50 FTIR (Thermo Fisher Scientific) spectrophotometer.

X-ray diffractometry: XRD pattern of MLX, $\beta-C D$, TEA, MLX- $\beta-C D$ binary complex, MLX- $\beta$-CD-TEA ternary complexes and physical mixtures of MLX- $\beta$-CD-TEA were determined using Rigaku Ultima IV X-ray diffractometer. $\mathrm{CuK}_{\alpha}$ radiation was used in the wavelength $1.54060 \AA$. The samples were step scanned between 0 and $70^{\circ}$ at $2 \theta$ scale while measuring the intensities of the diffraction peaks.

Scaning electron microscopy: The surface morphology of the MLX, $\beta-C D$, physical mixture and selected inclusion complexes were examined by scanning electron microscopy (SEM). Samples were fixed on the brass stub using doublesided tape and made electrically conductive by coating with a thin layer of gold by sputter coater (ion sputter). ePhotographs were taken at an electric voltage of $20 \mathrm{kV}$.

in vitro Dissolution study: Dissolution studies were carried out in a USP XXIV rotating paddle apparatus ( 8 basket Dissolution Test Station, Electrolab, India) at $37^{\circ} \mathrm{C}$ using the paddle method at $50 \mathrm{rpm}$ for meloxicam alone and for MLX- $\beta-C D$ binary complex, MLX- $\beta$-CD-TEA ternary complexes and physical mixtures of MLX- $\beta$-CD-TEA by powder dispersion method [36]. Quantities sufficient of each powder which were equivalent to $15 \mathrm{mg}$ of meloxicam were placed in the $500 \mathrm{~mL}$ of dissolution medium ( $\mathrm{pH}$ 1.2), which was prepared and degassed using a media preparator (EMP-21 DO, Electrolab, India). $5 \mathrm{~mL}$ samples were withdrawn at preset time intervals and analyzed spectrophotometrically at $362 \mathrm{~nm}$. After each sampling the fresh dissolution medium was added to maintain a sink condition.

Preparation of buoyant in situ gels: Buoyant in situ gels of MLX- $\beta$-CD-TEA ternary complex were prepared as per the reported method [37]. Weighed quantity of gellan gum was transferred to a beaker containing half of the total volume of double distilled water, which contains $0.25 \%$ w/v of sodium citrate. The contents of the beaker were heated to $90{ }^{\circ} \mathrm{C}$ with continuous stirring on a magnetic stirrer until a clear solution is obtained and then the solution was allowed to cool below $40{ }^{\circ} \mathrm{C}$. Calculated amounts of calcium carbonate and MLX$\beta$-CD-TEA ternary complex were dissolved in the second half of the double distilled water in a separate beaker and this solution is slowly with continuous stirring added to the cooled gellan gum solution. Finally the in situ gelling solution obtained was stored in an amber coloured glass bottle in a cool place until further investigation.
Optimization: Based on phase solubility and in vitro dissolution studies MLX- $\beta$-CD-TEA ternary complex (1:1:1molar ratio) was selected as one of the factors influencing the performance of buoyant in situ gels of meloxicam. The other two independent variables or factors, i.e. calcium carbonate and gellan gum were selected based on factor screening study. The Box-Behnken experimental design was employed to optimize the floating in situ gelling solutions wherein the concentrations of calcium carbonate (A), gellan gum (B) and MLX- $\beta$-CD-TEA ternary complex (C) were selected as independent variables or factors. Each factor was kept as low, medium and high levels. Floating lag time, Viscosity and percent cumulative drug release at $6^{\text {th }} \mathrm{h}$ were taken as dependent variables or responses (Table-1). The effect of factors on the observed responses was analyzed employing Design expert version 10.0.3. (Stat-Ease, Inc, USA) software. Fifteen experimental runs obtained from the design with 3 middle points with their observed and predicted responses are depicted in Table-2. The responses were statistically analyzed by ANOVA test method. The optimum formulation was chosen by the numerical optimization process using the desirability function. In order to assess the impact of each factor on the observed responses, the polynomial coefficients for in situ gelling solutions were ascertained. The polynomial equation generated by this experimental design is as follows:

$$
\begin{aligned}
Y= & b_{0}+b_{1} A+b_{2} B+b_{3} C+b_{12} A B+b_{13} A C+ \\
& b_{23} B C+b_{11} A^{2}+b_{22} B^{2}+b_{33} C^{2}
\end{aligned}
$$

where $\mathrm{Y}$ is the response; $\mathrm{b}_{0}$ is the intercept; $\mathrm{b}_{1}-\mathrm{b}_{33}$ are the regression coefficients calculated from the observed experimental values; and $\mathrm{A}, \mathrm{B}$ and $\mathrm{C}$ are the coded levels of the factors. The terms $\mathrm{A}, \mathrm{B}$ and $\mathrm{C}_{\mathrm{i}}^{2}(\mathrm{i}=1,2$ or 3 ) constitute the interaction and quadratic terms respectively.

\section{in vitro evaluation of buoyant in situ gels of MLX- $\beta$-CD- TEA ternary complex}

Appearance: The colour and the clarity of the buoyant in situ gels of MLX- $\beta$-CD-TEA ternary complex was evaluated by the visual inspection of the solutions against a dark illuminating background.

pH measurement: The $\mathrm{pH}$ of buoyant in situ gels of MLX$\beta$-CD-TEA ternary complex was measured by a calibrated digital $\mathrm{pH}$ meter (HI-2214 logging $\mathrm{pH}$ bench meter, UK) at room temperature using $30 \mathrm{~mL}$ of the sample. $\mathrm{pH}$ determination for each sample was performed in triplicate.

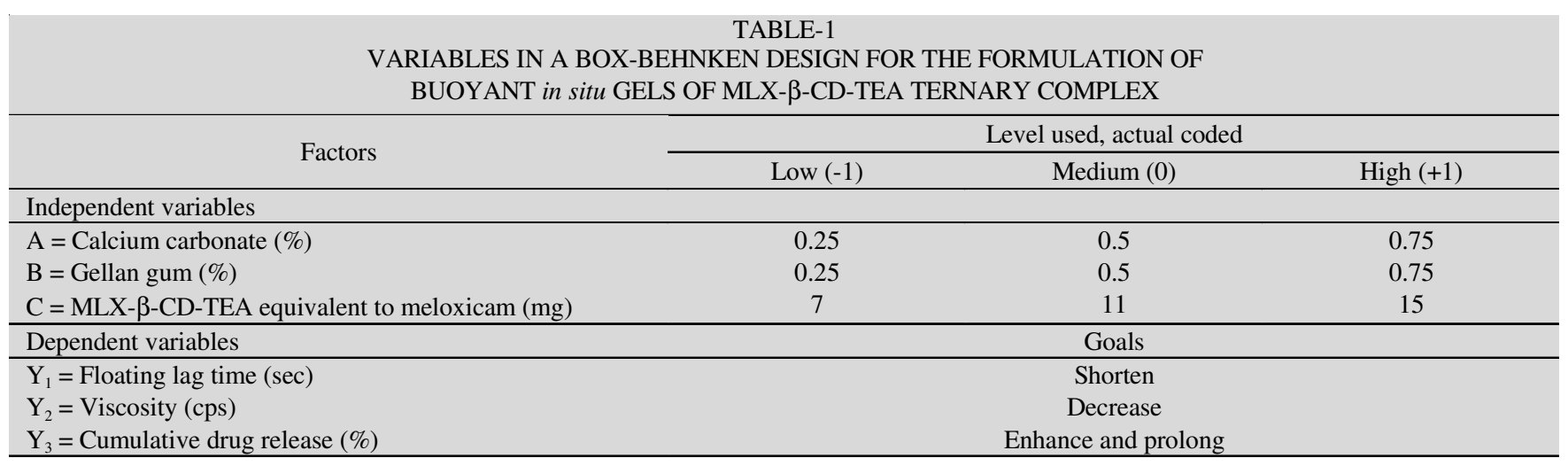


TABLE-2

OBSERVED RESPONSE IN BOX-BEHNKEN DESIGN FOR BUOYANT in situ GELS OF MLX- $\beta$-CD-TEA TERNARY COMPLEX

\begin{tabular}{cccc|cc|cc|cc}
\hline \multirow{2}{*}{ Run No. } & \multicolumn{3}{c}{ Variables* } & \multicolumn{2}{c|}{ Floating lag time (min) } & \multicolumn{2}{c|}{ Viscosity (cps) } & \multicolumn{2}{c}{ Cumulative drug release $(\%)$} \\
\cline { 2 - 9 } & A & B & C & Actual & Predicted & Actual & Predicted & Actual & Predicted \\
\hline 1 & 0.75 & 0.75 & 11 & 0.9 & 0.88 & 1250 & 1251.00 & 67 & 66.88 \\
2 & 0.25 & 0.50 & 7 & 6.1 & 6.10 & 501 & 501.88 & 86 & 85.75 \\
3 & 0.25 & 0.25 & 11 & 6.1 & 6.13 & 200 & 199.00 & 98 & 98.13 \\
4 & 0.50 & 0.50 & 11 & 3.0 & 3.00 & 520 & 520.00 & 81 & 81.00 \\
5 & 0.50 & 0.25 & 15 & 3.0 & 2.98 & 224 & 225.13 & 95 & 94.88 \\
6 & 0.50 & 0.75 & 15 & 3.0 & 3.03 & 1245 & 1244.87 & 70 & 69.88 \\
7 & 0.75 & 0.25 & 11 & 0.7 & 0.72 & 210 & 209.75 & 92 & 91.88 \\
8 & 0.75 & 0.50 & 15 & 0.8 & 0.80 & 551 & 550.13 & 79 & 79.25 \\
9 & 0.75 & 0.50 & 7 & 0.8 & 0.80 & 525 & 525.13 & 78 & 78.00 \\
10 & 0.25 & 0.75 & 11 & 6.1 & 6.08 & 1200 & 1200.25 & 73 & 73.13 \\
11 & 0.50 & 0.50 & 11 & 3.0 & 3.00 & 520 & 520.00 & 81 & 81.00 \\
12 & 0.50 & 0.75 & 7 & 3.0 & 3.03 & 1230 & 1228.87 & 70 & 70.13 \\
13 & 0.25 & 0.50 & 15 & 6.1 & 6.10 & 512 & 511.88 & 84 & 84.00 \\
14 & 0.50 & 0.25 & 7 & 3.0 & 2.98 & 206 & 206.13 & 95 & 95.13 \\
15 & 0.50 & 0.50 & 11 & 3.0 & 3.00 & 520 & 520.00 & 81 & 81.00 \\
\hline
\end{tabular}

*A, Calcium carbonate; *B, Gellan gum; *C, MLX- $\beta$-CD-TEA ternary complex

Viscosity measurement: The viscosity of buoyant in situ gels of MLX- $\beta$-CD-TEA ternary complex was determined by a Viscometer (SV-10 Japan) at room temperature using $30 \mathrm{~mL}$ of the sample. Viscosity determination for each sample was done in triplicate.

\section{in vitro Gelation study}

in vitro Gelation study was conducted on buoyant in situ gels of MLX- $\beta$-CD-TEA ternary complex as described in the literature [38]. $10 \mathrm{~mL}$ of the gelling solution was transferred to $500 \mathrm{~mL}$ of $0.1 \mathrm{~N} \mathrm{HCl}(\mathrm{pH} 1.2)$ in a beaker without much turbulence to prevent shattering of the formed gel. Gelling was observed in the beaker by visual inspection and the formulations based on their gelling consistency were given with different grades.

in vitro Buoyancy study: in vitro buoyancy study of in situ gels of MLX- $\beta$-CD-TEA ternary complex was conducted as per the reported method [39]. $500 \mathrm{~mL}$ of the dissolution medium ( $\mathrm{pH}$ 1.2) is taken in a dissolution flask (USP Type-II) and the temperature of the dissolution medium was maintained at $37 \pm 0.5{ }^{\circ} \mathrm{C}$. $10 \mathrm{~mL}$ of the solution is transferred to a Petri dish ( $4.5 \mathrm{~mm}$ internal diameter) and the Petri dish is carefully placed at the bottom of a dissolution flask without much disturbance in the flask. The time taken by the in situ gel to come up to the surface of the medium (floating lag time) and also about how much time the gel continuously floated on the surface of the medium (duration of floating) was recorded.

in vitro Drug release study: in vitro Release of meloxicam from the buoyant in situ gels of MLX- $\beta$-CD-TEA ternary complex was determined in a USP XXIV rotating paddle apparatus ( 8 basket Dissolution Test Station, Electrolab, India) at $37{ }^{\circ} \mathrm{C}$ using the paddle method at $50 \mathrm{rpm}$. The dissolution medium used was $500 \mathrm{~mL}$ of $0.1 \mathrm{~N}$ hydrochloric acid $(\mathrm{pH}$ 1.2) which was prepared and degassed using a media preparator (EMP-21 DO, Electrolab, India). The in situ gel is added to a Petri dish $(4.5 \mathrm{~mm}$ internal diameter) and the Petri dish is then transferred to the bottom of a dissolution basket without much disturbance. $5 \mathrm{~mL}$ samples were withdrawn at fixed time intervals and analyzed at $362 \mathrm{~nm}$ using UV-visible spectro- photometer (BT-600 UK). After each withdrawal an immediate replacement of $5 \mathrm{~mL}$ fresh dissolution medium was done to maintain a sink condition. Each determination was performed in triplicate till $6 \mathrm{~h}$.

in vivo Anti-inflammatory activity: Carrageenan induced rat hind paw edema method [40] was used to assess the antiinflammatory activity of optimized buoyant in situ gels of MLX- $\beta$-CD-TEA ternary complex. The experimental protocol was approved by the Institutional Review Board and Animal Ethical Committee of the University of Dammam, Kingdom of Saudi Arabia (Approval number: IRB-2014-3-199).

Animals: Wistar rats of either sex weighing 200-250 g were used in the present study. The selected animals were housed in polypropylene cages under standard laboratory conditions (temperature $25 \pm 2{ }^{\circ} \mathrm{C}$ ) with a cycle of $12 \mathrm{~h}$ of darkness and light. The animals were fed with standard diet and water ad libitum and were fasted for at least $12 \mathrm{~h}$ prior to the experiment.

Carrageenan induced rat hind paw edema method: Rats were divided into three groups, each group has six rats. The animals of group I received $1 \mathrm{~mL}$ of control [calcium carbonate/gellan gum $(0.75 \% \mathrm{w} / \mathrm{v} / 0.25 \% \mathrm{w} / \mathrm{v})]$ p.o. and groups II and III received p.o. standard [calcium carbonate/gellan gum/ pure meloxicam $(0.75 \% \mathrm{w} / \mathrm{v} / 0.25 \% \mathrm{w} / \mathrm{v} / 11 \mathrm{mg})]$ and optimized buoyant in situ gel [calcium carbonate/gellan gum/ $(0.75 \%$ w/ $\mathrm{v} / 0.25 \% \mathrm{w} / \mathrm{v} / \mathrm{MLX}-\beta-\mathrm{CD}-\mathrm{TEA}$ ternary complex equivalent to $11 \mathrm{mg}$ of meloxicam)] respectively (dose of meloxicam: 1 $\mathrm{mg} / \mathrm{kg}$ body weight). After $1 \mathrm{~h}$ of the test drug and the control treatment animals of group I, II and III were injected with subcutaneous injection of $0.1 \mathrm{~mL}$ of $1 \% \mathrm{w} / \mathrm{v}$ solution of carrageenan (Sigma Chemical Co, St. Louis MO, USA) in normal saline into the plantar side of the left hind paw. Plethysmograph (UGO Basile, Italy) was used to measure the rat paw volume. The paw volume was measured before $(0) \mathrm{h}$ and $1,2,3,4$ and $6 \mathrm{~h}$ after the injection of carrageenan.

The edema inhibitory activity was computed using the following formula:

$$
\text { Edema inhibition }(\%)=\left(1-\frac{\mathrm{D}}{\mathrm{C}}\right) \times 100
$$


where, D represents the percentage difference in increased paw volume after the administration of test drugs to the rats. $\mathrm{C}$ represents the percentage difference of increased volume in the control groups.

Stability study: Optimized in situ gel of MLX- $\beta-C D-$ TEA ternary complex was packed in glass bottles and stored at accelerated temperature and humidity $\left(40 \pm 2{ }^{\circ} \mathrm{C} / 75 \% \pm 5\right.$ $\mathrm{RH}$ ) in the stability chamber for 3 months. Small amounts of samples from each bottle were removed after 0, 1, 2 and 3 months and evaluated for appearance, $\mathrm{pH}$, floating lag time, viscosity and in vitro drug release.

\section{RESULTS AND DISCUSSION}

Phase solubility studies: Phase solubility graphs of MLX$\beta-C D$ and MLX- $\beta$-CD-TEA complexes are illustrated in Fig. 1. According to Higuchi and Connors classification, the graphs were classified as $A_{L}$ type, which revealed the formation of 1:1 soluble complexes in the presence or absence of TEA. The apparent stability constant $\left(\mathrm{K}_{\mathrm{c}}\right)$ values obtained were 166.2 $\mathrm{M}^{-1}$ for MLX- $\beta$-CD binary complex and $235.6 \mathrm{M}^{-1}$ for MLX$\beta$-CD-TEA ternary complex. The Kc values specify that the stability of the MLX- $\beta$-CD-TEA ternary complex is greater than that of MLX- $\beta-C D$ binary complex. The incorporation of TEA greatly increased the solubilizing potential of $\beta-C D$. The mechanism involved in enhancing the solubility of meloxicam could be ascribed to the synergistic effect of salt formation and inclusion in $\beta$-cyclodextrin.

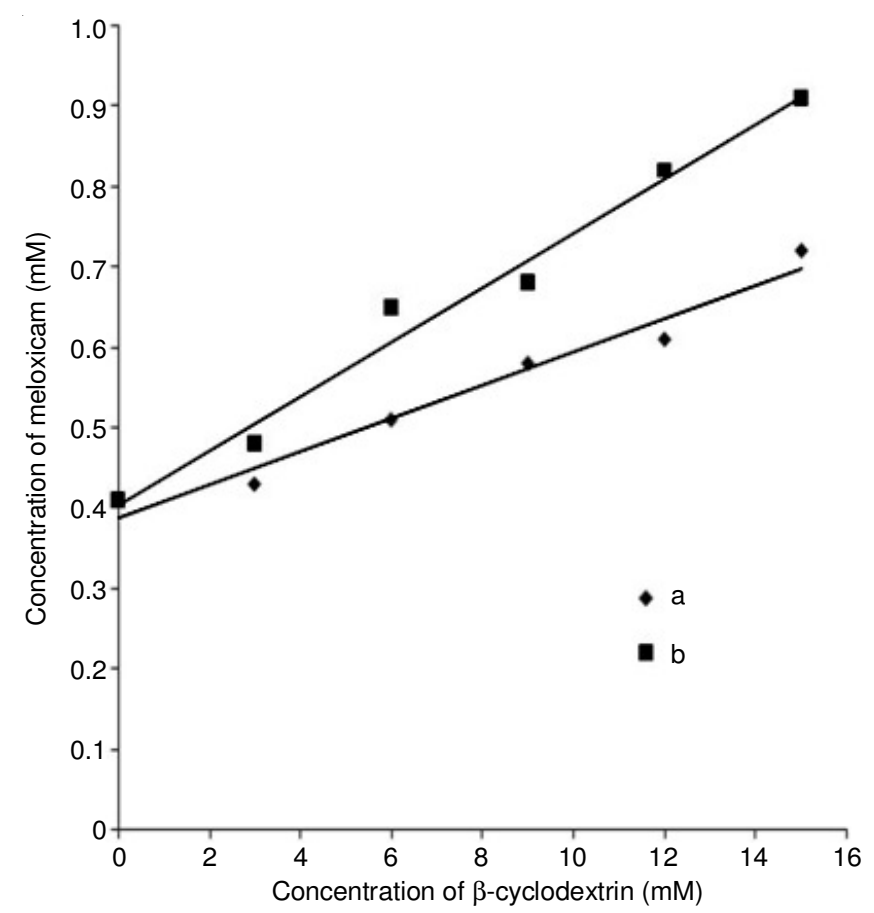

Fig. 1. Phase solubility graphs of MLX- $\beta-C D$ (a) and MLX- $\beta-C D-T E A$ complexes (b)

\section{Characterization of raw materials and solid complexes of meloxicam}

Fourier transformed infrared spectroscopy: FTIR spectrum of meloxicam (Fig. 2a) showed distinct peaks at $3291.86 \mathrm{~cm}^{-1}$ (Secondary-NH or $\left.-\mathrm{OH}\right), 1621.02 \mathrm{~cm}^{-1}(\mathrm{C}=\mathrm{O}$ stretching), $1347.09 \mathrm{~cm}^{-1}$ ( $\mathrm{S}=\mathrm{O}$ stretching) and $855.75 \mathrm{~cm}^{-1}$ to $565.18 \mathrm{~cm}^{-1}$ (-CH aromatic ring bending and heteroaromatics). FTIR spectrum of $\beta$-cyclodextrin (Fig. 2b) showed distinct peaks at $3315.43 \mathrm{~cm}^{-1}$ (O-H stretching), $1154.25 \mathrm{~cm}^{-1}$ and $1078.81 \mathrm{~cm}^{-1}, 1026.48 \mathrm{~cm}^{-1}$ (-OH and $\mathrm{C}-\mathrm{O}$ respectively). In the FTIR spectrum of MLX- $\beta$-CD-TEA physical mixture (Fig. $2 \mathrm{c}$ ) the characteristic $-\mathrm{NH}$ or $-\mathrm{OH}$ absorption was shifted and broadened, whereas this absorption is disappeared in binary (Fig. 2d) and ternary (Fig. 2e) complexes of meloxicam. Moreover, appearance of new peaks in the FTIR spectra of physical mixture and in solid binary and ternary complexes indicates inclusion complex formation. These results also indicate that an intermolecular interaction has occurred between meloxicam and triethanolamine resulting in salt formation. The salt formation could be due to an electrostatic interaction between negative charge of the oxygen atom of meloxicam and positive charge of the triethanolamine nitrogen.
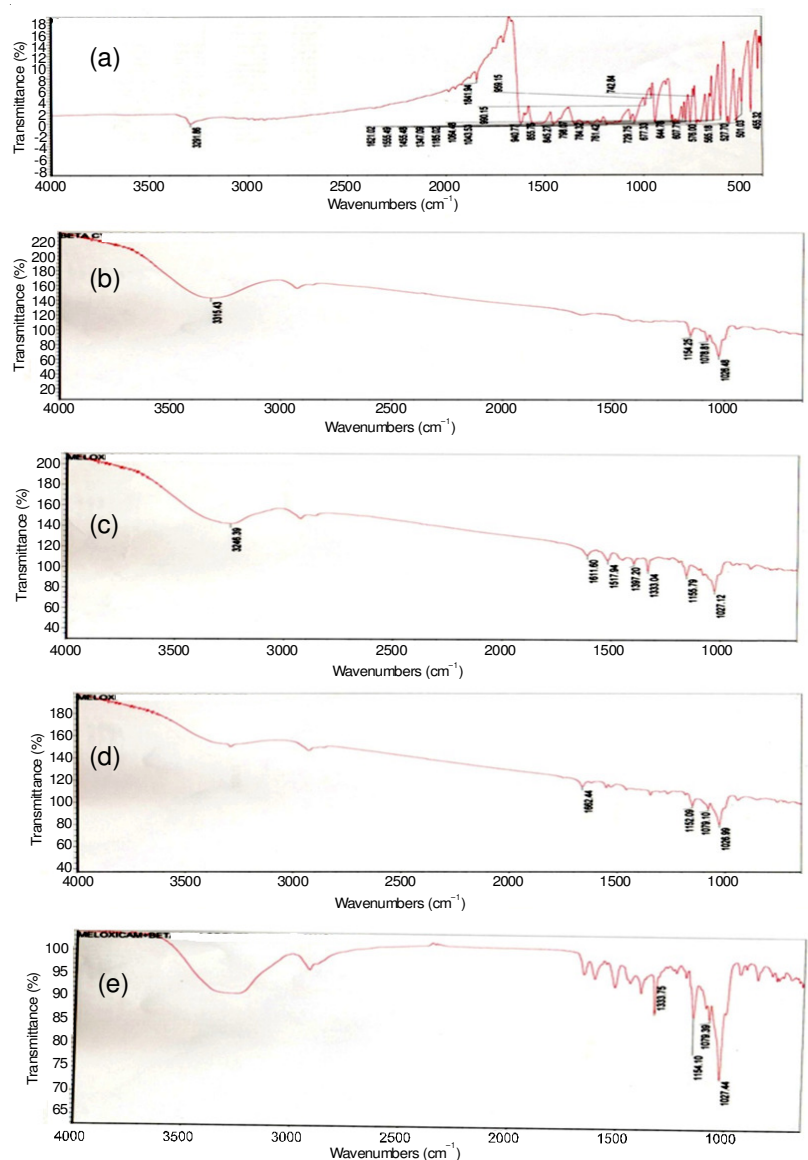

Fig. 2. FTIR spectrum of meloxicam (MLX) (a), $\beta$-cyclodextrin $(\beta-\mathrm{CD})$ (b), MLX- $\beta$-CD-TEA physical mixture (c), MLX- $\beta$-CD binary complex (d) and MLX- $\beta$-CD-TEA ternary complex (e)

X-ray diffractometry: The diffractogram of pure meloxicam (Fig. 3a) showed characteristic peaks at $13^{\circ}, 14.8^{\circ}, 18.5^{\circ}$ and $25.8^{\circ}$ due to its crystalline nature. Series of intense peaks at $4.46^{\circ}, 8.9^{\circ}, 12.4^{\circ}, 17.1^{\circ}, 22.7^{\circ}, 25.6^{\circ}$ and $39.2^{\circ}$ observed in the diffractogram of $\beta$-cyclodextrin (Fig. 3b) are indicative of its crystalline nature. Most of the principal peaks of both pure meloxicam and $\beta$-cyclodextrin are present in the MLX- $\beta$-CDTEA physical mixture (Fig. 3c) indicates no major interaction between meloxicam, $\beta$-cyclodextrin and triethanolamine. 
In contrast to these results, the X-ray diffractograms of both MLX- $\beta-C D$ binary complex (Fig. 3d) and MLX- $\beta$-CD-TEA ternary complex (Fig. 3e) showed significant changes in the crystalline nature of meloxicam. Reduction of peak intensity with slightly shifting of peaks of pure meloxicam at $18.5^{\circ}$ and $25.8^{\circ}$ and forming new peaks such as that at $19.3^{\circ}$ and $29.5^{\circ}$ in MLX- $\beta$-CD-TEA ternary complex is an example of these changes. These results are indicative of a reduction in crystallinity of meloxicam in MLX- $\beta$-CD-TEA ternary complex, which might be because of combined effect of salt formation and inclusion complex formation between meloxicam, triethanolamine and $\beta$-cyclodextrin.

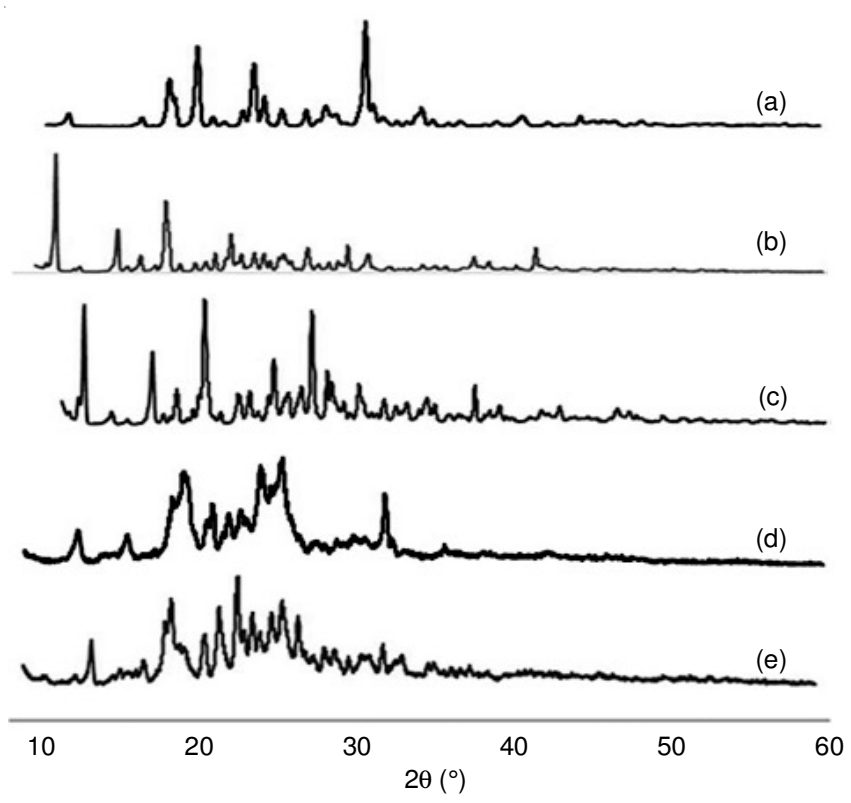

Fig. 3. XRD spectra of meloxicam (MLX) (a), $\beta$-cyclodextrin ( $\beta$-CD) (b), MLX- $\beta$-CD-TEA physical mixture (c), MLX- $\beta$-CD binary complex (d) and MLX- $\beta$-CD-TEA ternary complex (e)

Scanning electron microscopy: From the SEM images (Fig. 4a), pure MLX particles appeared as crystalline, $\beta-C D$ particles (Fig. 4b) appeared like cluster structure. Microscopic observation of ternary physical mixture (MLX- $\beta$-CD-TEA) (Fig. 4c) showed the presence of MLX crystals adhered to the surface of $\beta-C D$ particle revealing no apparent interaction between both powders in the solid state. Binary and ternary inclusion complexes (Fig. 4d and 4e) showed a small and irregular piece and like inclusion of material in the cavity. Pandya et al. [41] have reported that a modification in the shape of drug particles was indicative of a new solid state. Thus, changes in the morphology of complex as compared to drug showed interaction between MLX and a complexing agent. These results are consistent with the XRD results.

in vitro Dissolution study: Dissolution profiles of pure meloxicam, MLX- $\beta$-CD binary complex, MLX- $\beta-C D-T E A$ physical mixtures and ternary complexes are depicted in Fig. 5 . Both binary and ternary complexes of meloxicam exhibited improved dissolution as compared to pure meloxicam and physical mixtures. The trend observed for percent dissolution of meloxicam from physical mixtures and ternary complexes was an increase in the dissolution rate by an increase in triethanolamine concentration. However the physical mixture
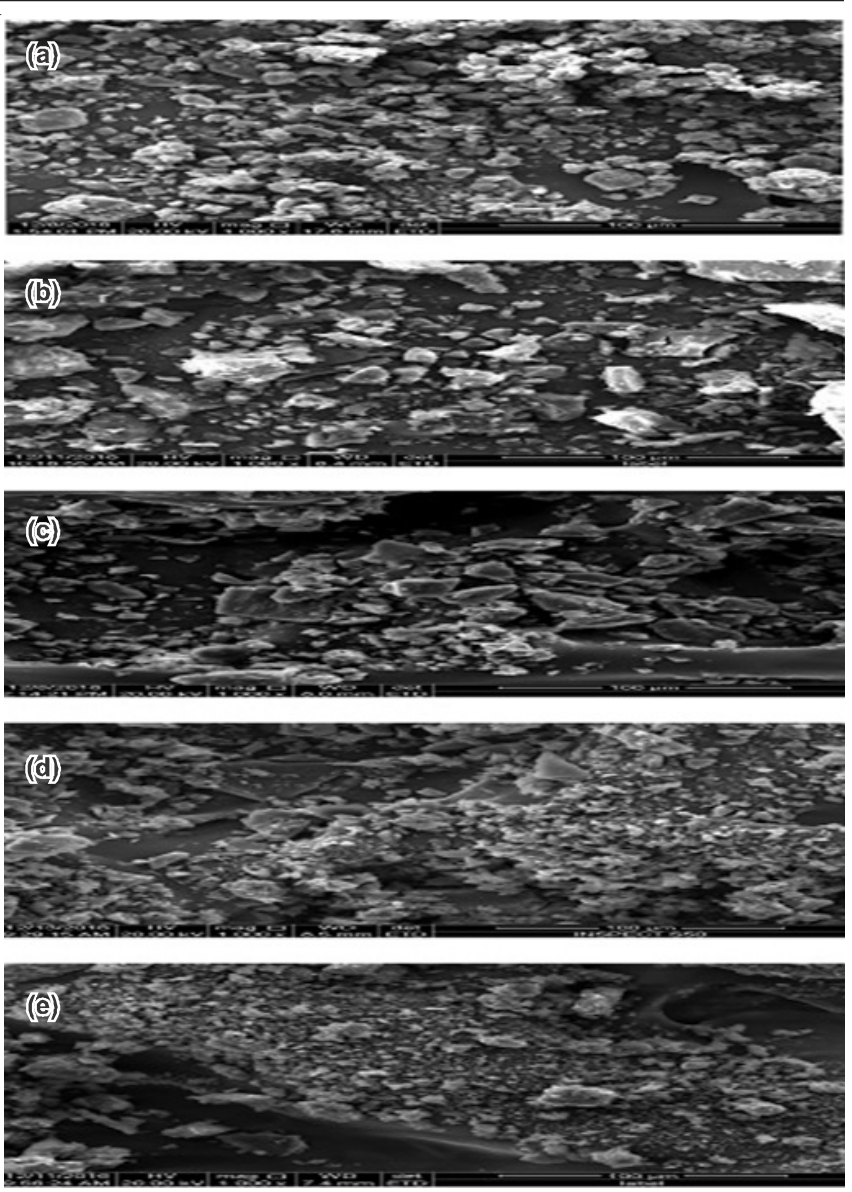

Fig. 4. SEM images of meloxicam (MLX) (a), $\beta$-cyclodextrin ( $\beta$-CD) (b), MLX- $\beta$-CD-TEA physical mixture (c), MLX- $\beta$-CD binary complex (d) and MLX- $\beta$-CD-TEA ternary complex (e)

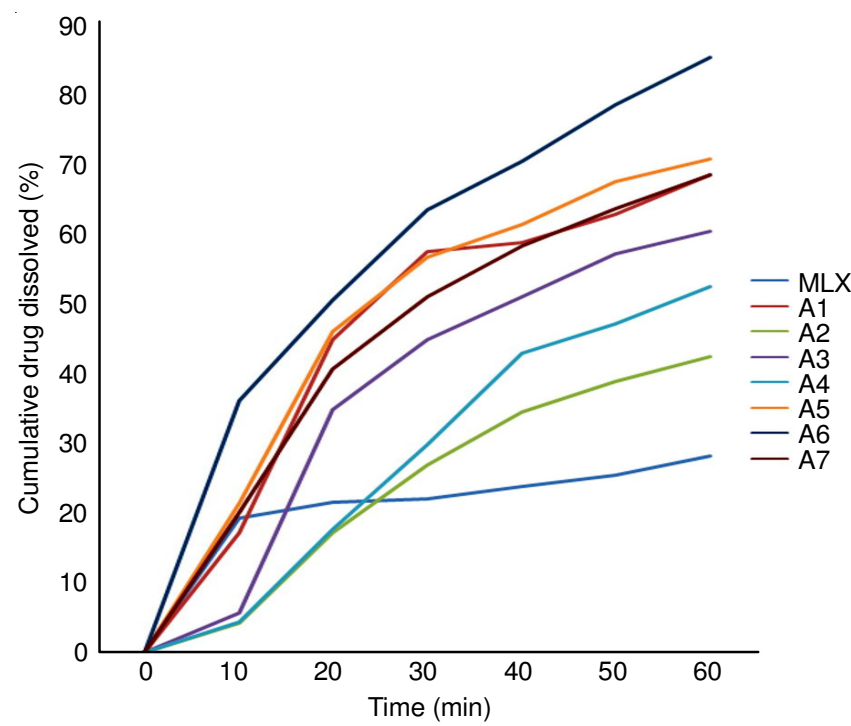

Fig. 5. in vitro dissolution profiles of pure meloxicam (MLX), MLX- $\beta$ CD binary complex (A1), MLX- $\beta$-CD-TEA physical mixtures (A2 to A4) and MLX- $\beta$-CD-TEA ternary complexes (A5 to A7)

and the ternary complex containing 1:1:1.5 molar ratio of MLX- $\beta$-CD-TEA respectively showed decreased rate and extent of drug dissolution as compared to the physical mixtures and the ternary complexes containing 1:1:0.5 and 1:1:1 molar ratios of MLX- $\beta-C D-T E A$ respectively. It may be imputed to salting out effect due to the presence of higher concentration 
of TEA in the complexes. MLX- $\beta$-CD-TEA ternary complex (1:1:1 molar ratio) showed comparatively highest drug dissolution. The mechanisms of dissolution of meloxicam from the physical mixtures and complexes were studied. The data was used to study the best linear fit for the following equations [42]: (1) Zero order, (2), First order, (3) Matrix (Higuchi matrix), (4) Peppas-Korsmeyer equation, (5) Hixson-Crowell equation:

$$
\mathrm{R}(\%)=\mathrm{K}_{\mathrm{t}}
$$

$\log \%$ unreleased $=\mathrm{K}_{\mathrm{t}} / 2.303$

$$
\mathrm{R}(\%)=\mathrm{Kt} 0.5
$$

\section{Amount of drug released at time $\mathrm{t}$}

Amount of drug released at time ' $\infty$ ' $=K_{t} n$

$$
\text { (\% unreleased) } 1 / 3=K_{t}
$$

where ' $n$ ' is the diffusion coefficient, which is suggestive of transport mechanism.

The dissolution mechanism of the complex with highest rate and extent of drug dissolution was found to be the first order type $(r=0.99870, a=0.00820$ and $b=1.97610)$. The $\mathrm{r}$, a and b are correlation coefficient, slope and constant, respectively, for the best fit kinetic model.

Post-characterization and in vitro evaluation, MLX- $\beta$-CDTEA ternary complex (1:1:1 molar ratio) was selected to prepare and evaluate its floating in situ gelling solutions.

Optimization: Fifteen buoyant in situ gels of MLX- $\beta$ CD-TEA ternary complex were developed according to the experimental design and characterized by different responses such as floating lag time, viscosity and drug release. The mathematical correlations were set up and coefficients of the second order polynomial equations were derived using multiple linear regression analysis for a floating lag time, viscosity and drug release were found to be quadratic in nature with interaction terms. The coefficients of the polynomials fit well to the data, with the values of $\mathrm{R}^{2}$ ranging between 0.9995 and 0.9999 ( $\mathrm{p}<0.0009$ in all cases). The three dependent values ranged from 0.7 to $6.1 \mathrm{~min}, 200$ to $1250 \mathrm{cps}$ and 67 to $98 \%$ floating lag time, viscosity and drug release, respectively. A positive value in polynomial equations corresponds to an effect that favours the optimization, whereas a negative value represents an inverse relationship between the factor and the response. The polynomial equations derived by the statistical analysis of the results are given in Table-3. Where A, B and C corresponds to the coded values of the calcium carbonate, gellan gum and meloxicam, respectively. The effect of calcium carbonate on floating lag time is comparatively more significant than the effect of gellan gum. Other independent variable meloxicam has not shown any significant change in the floating lag time of in situ gelling solutions. All three independent variables, namely calcium carbonate, gellan gum and meloxicam individually and also in combinations (calcium carbonate + gellan gum, calcium carbonate + meloxicam) have the positive effect on viscosity. But the effect of the said variables is negative on drug release. This could be due to sol to gel transformation of the formulations in an acidic medium.

All the responses studied for fifteen ternary complexes in situ gel formulations were collectively fitted to various models using Design Expert version 10.0.3. (Stat-Ease, Inc, USA). The best-fitted model of the three factors and their comparative values of $\mathrm{R}^{2}$ predicted $\mathrm{R}^{2}$, adjusted $\mathrm{R}^{2}, \mathrm{SD}$ and $\% \mathrm{CV}$ are given in Table-3. The "predicted $\mathrm{R}^{2}$ " was more or less in accordance

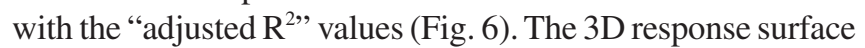
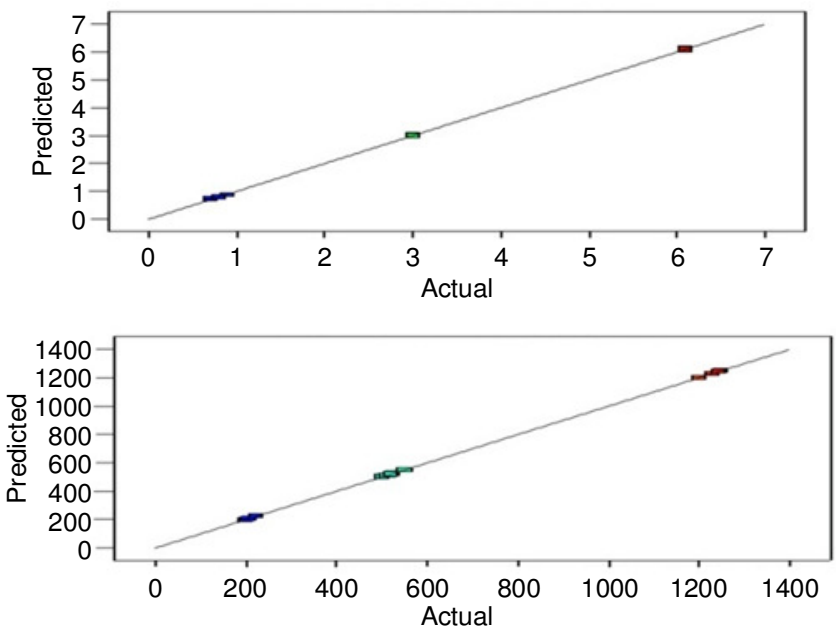

\begin{tabular}{|c|c|c|c|c|c|}
\hline \multicolumn{6}{|c|}{$\begin{array}{c}\text { TABLE-3 } \\
\text { MODEL SUMMARY STATISTICS GIVEN BY A BOX-BEHNKEN DESIGN }\end{array}$} \\
\hline Model & $\mathrm{R}^{2}$ & Adjusted $\mathrm{R}^{2}$ & Predicted $\mathrm{R}^{2}$ & SD & $\mathrm{CV}(\%)$ \\
\hline \multicolumn{6}{|c|}{ Floating lag time $=+3.00-2.65 * \mathrm{~A}+0.025 * \mathrm{~B}+0.000 * \mathrm{C}+0.050 * \mathrm{AB}+0.000 * \mathrm{AC}+0.000 * \mathrm{BC}+0.45 * \mathrm{~A}^{2}+0.000 * \mathrm{~B}^{2}+0.000 * \mathrm{C}^{2}$} \\
\hline Linear & 0.9865 & 0.9828 & 0.9740 & 0.26 & \multirow{3}{*}{0.98} \\
\hline 2FI & 0.9866 & 0.9766 & 0.9415 & 0.31 & \\
\hline Quadratic & 0.9999 & 0.9998 & 0.9986 & 0.032 & \\
\hline \multicolumn{6}{|c|}{ Viscosity $=+520.00+15.38 * \mathrm{~A}+510.62 * \mathrm{~B}+8.75 * \mathrm{C}+10.00 * \mathrm{AB}+3.75 * \mathrm{AC}-0.75 * \mathrm{BC}-4.50 * \mathrm{~A}^{2}+199.50 * \mathrm{~B}^{2}+6.75^{*} \mathrm{C}^{2}$} \\
\hline Linear & 0.9334 & 0.9152 & 0.8727 & 116.41 & \multirow{3}{*}{0.18} \\
\hline $2 \mathrm{FI}$ & 0.9336 & 0.8838 & 0.7111 & 136.30 & \\
\hline Quadratic & 1.0000 & 1.0000 & 1.0000 & 1.12 & \\
\hline \multicolumn{6}{|c|}{ Cumulative \% Drug Release $\left(6^{\text {th }} \mathrm{h}\right)=+81.00-3.13^{*} \mathrm{~A}-12.50 * \mathrm{~B}-0.13 * \mathrm{C}+0.000 * \mathrm{AB}+0.75^{*} \mathrm{AC}+0.000 * \mathrm{BC}+0.38^{*} \mathrm{~A}^{2}+1.13^{*} \mathrm{~B}^{2}+0.37 * \mathrm{C}^{2}$} \\
\hline Linear & 0.9942 & 0.9926 & 0.9898 & 0.84 & \multirow{3}{*}{0.27} \\
\hline $2 \mathrm{FI}$ & 0.9959 & 0.9928 & 0.9875 & 0.83 & \\
\hline Quadratic & 0.9998 & 0.9995 & 0.9970 & 0.22 & \\
\hline
\end{tabular}

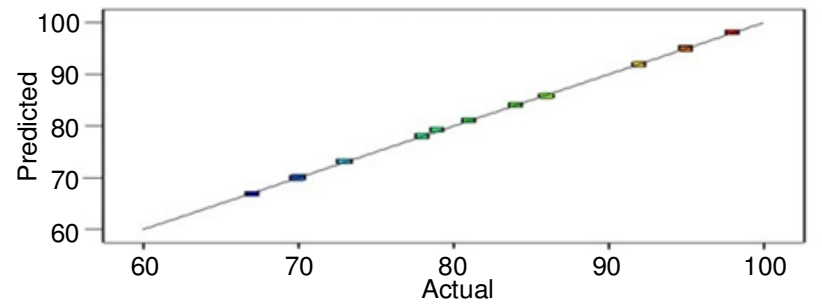

Fig. 6. Actual vs. predicted values 
graphs presenting the interaction effects of the factors on the responses are illustrated in Fig. 7. The fitting results showed that the optimized in situ gels of MLX- $\beta$-CD-TEA ternary complex with short floating lag time ( $0.7 \mathrm{~min})$, low viscosity (210 cps) and high drug release at the 6th hour (92\%) was obtained using an optimized combination of calcium carbonate $(0.75 \% \mathrm{w} / \mathrm{v})$, gellan gum $(0.25 \% \mathrm{w} / \mathrm{v})$ and meloxicam content $(11 \mathrm{mg})$, respectively. All the response surfaces were best fitted with quadratic polynomial models and are capable of predicting the interaction effects as well. Finally, the model was analyzed for ANOVA ( $\mathrm{p}<0.0001)$, which disclosed that the model terms for main effects and interaction effects were highly significant.

in vitro Evaluation of buoyant in situ gels: All the 15 ternary complexes in situ gels of MLX- $\beta$-CD-TEA ternary complex were clear, viscous and pale yellow in colour. The $\mathrm{pH}$ of the solutions was in the range of 6.8 to 7.5. The in situ gelling solutions containing $0.5 \%$ and above amount of calcium carbonate exhibited desired in vitro gelation property and also showed a long duration of floating on the surface of an acidic medium ( $\mathrm{pH}$ 1.2). This could be due to the free availability of a sufficient number of calcium ions and carbon dioxide content from the calcium carbonate in an acidic medium to boost the gelling potential of gellan gum and also induce floating characters in it (Table-4). These findings are consistent with the reported results [21].

The in situ gels demonstrated a considerable increase in viscosity with increasing amount of gellan gum. It was attributed to an increasing chain interaction with gellan gum concentration. Similarly, an increase in the amount of calcium carbonate also increases the viscosity of the in situ gels at all three gellan gum percentage. It could be due to the high concentration of finely dispersed particles of calcium carbonate in the gelling solution. On the other hand, meloxicam has not contributed much in increasing the viscosity of in situ gels as it was in its freely soluble ternary complex form with $\beta$-cyclodextrin and triethanolamine.

A marked decline in the rate and extent of in vitro drug release was noted with the increase in gellan gum concentration in in situ gels (Fig. 8). It is attributed to the high density of the system and also to the increase in the drug's diffusional path length. In order to study the drug release mechanism, the in vitro release data obtained were fitted to various kinetic equations. The release model of optimized in situ gel formulation followed Matrix (Higuchi matrix) kinetics with a best-fit $r$ value 0.9698 , a value 12.3273 and $b$ value 8.0428 .
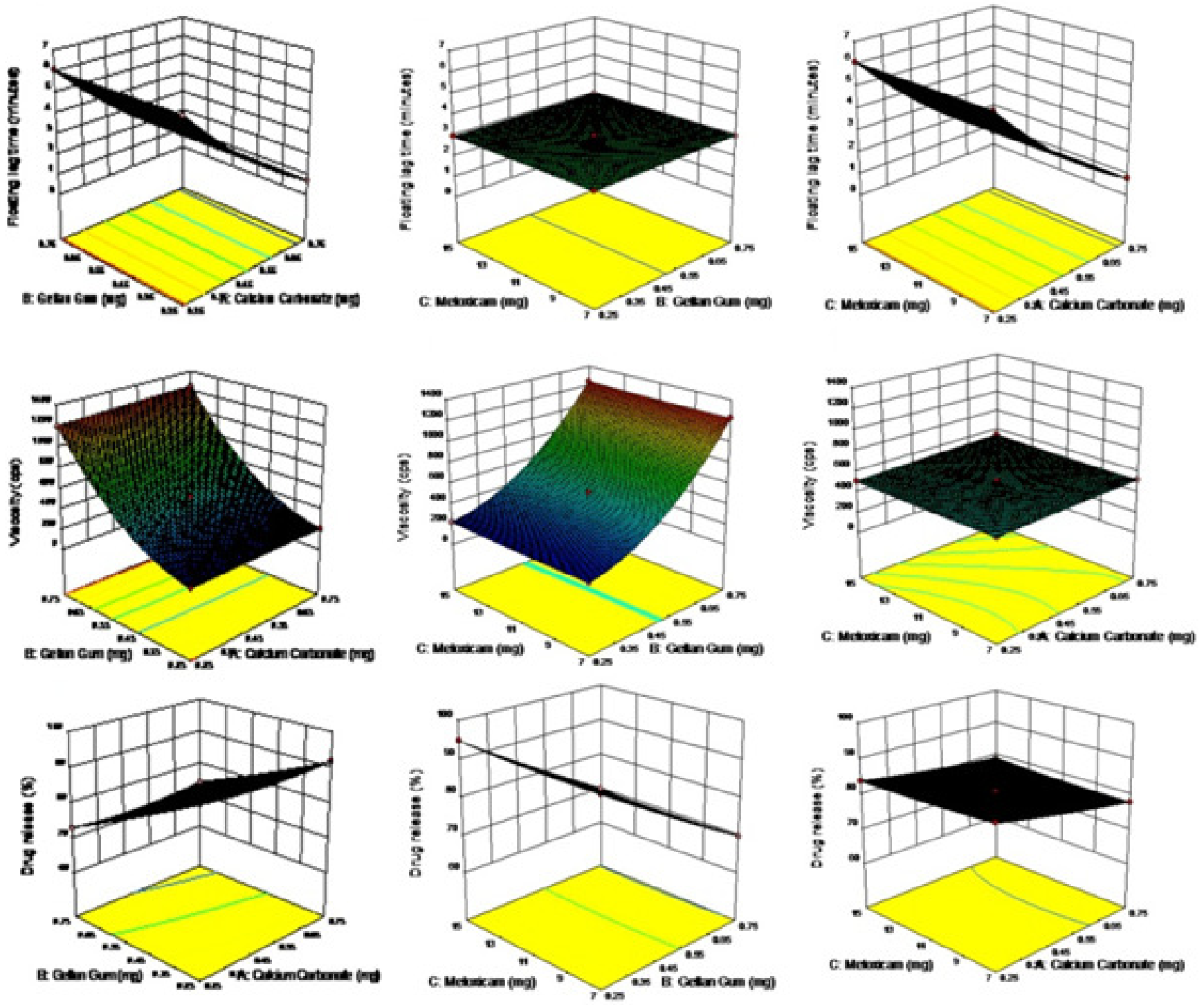

Fig. 7. 3D graphs of independent variables 


\begin{tabular}{|c|c|c|c|c|c|}
\hline \multicolumn{6}{|c|}{$\begin{array}{c}\text { TABLE-4 } \\
\text { in vitro EVALUATION OF BUOYANT in situ GELS OF MLX- } \beta-C D-T E A \text { TERNARY COMPLEX }\end{array}$} \\
\hline $\begin{array}{l}\text { Formulation } \\
\text { Code/Run No. }\end{array}$ & Clarity & Colour & $\mathrm{pH}$ & Gelation ( $\mathrm{pH}$ 1.2) & Duration of floating (h) \\
\hline F1 & Clear & Pale yellow & 7.4 & Very good & $>24$ \\
\hline $\mathrm{F} 2$ & Clear & Pale yellow & 7.2 & Poor & $<1$ \\
\hline F3 & Clear & Pale yellow & 6.8 & Poor & $<1 \mathrm{~h}$ \\
\hline F4 & Clear & Pale yellow & 7.3 & Good & 12 \\
\hline F5 & Clear & Pale yellow & 7.0 & Good & 12 \\
\hline F6 & Clear & Pale yellow & 7.5 & Good & 12 \\
\hline F7 & Clear & Pale yellow & 6.9 & Very good & $>24$ \\
\hline F8 & Clear & Pale yellow & 7.2 & Very good & $>24$ \\
\hline F9 & Clear & Pale yellow & 7.3 & Very good & $>24$ \\
\hline F10 & Clear & Pale yellow & 7.2 & Poor & $<1$ \\
\hline F11 & Clear & Pale yellow & 7.3 & Good & 12 \\
\hline $\mathrm{F} 12$ & Clear & Pale yellow & 7.2 & Good & 12 \\
\hline F13 & Clear & Pale yellow & 7.1 & Poor & $<1$ \\
\hline F14 & Clear & Pale yellow & 6.8 & Good & 12 \\
\hline F15 & Clear & Pale yellow & 7.2 & Good & 12 \\
\hline
\end{tabular}

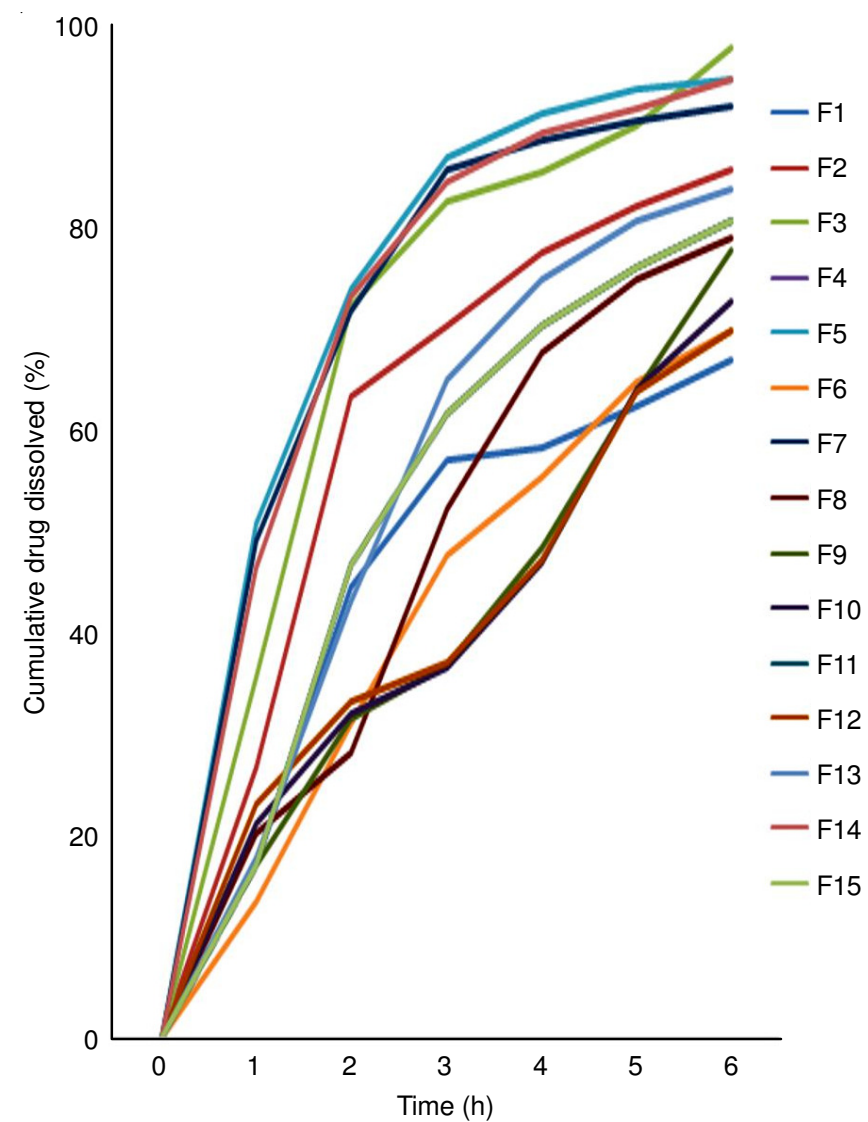

Fig. 8. in vitro drug release profile of buoyant in situ gels MLX- $\beta-C D$ TEA ternary complex in vivo Anti-inflammatory activity: The optimized floating in situ gel of MLX- $\beta$-CD-TEA ternary complex has showed significant inhibition of Carrageenan-induced rat paw edema from 2 to $6 \mathrm{~h}$ in rats following oral administration, as compared to the control and standard group of animals. The highest percentage of inhibition of standard drug pure meloxicam was found to be $59.37 \%(\mathrm{p}<0.05)$, whereas the optimized floating in situ gel of MLX- $\beta$-CD-TEA ternary complex exhibited the maximum percentage of inhibition of paw edema at $6 \mathrm{~h}$ is $84.38 \%$ ( $\mathrm{p}<$ 0.05) (Table-5), even though the standard drug has exhibited the significant inhibition of paw edema, but the optimized buoyant in situ gel has been found to be more significant $(\mathrm{p}<0.05)$ paw edema inhibition from $2 \mathrm{~h}$ to till $6 \mathrm{~h}$ as compared to the control and standard group of animals.

Stability study: Optimized buoyant in situ gel of MLX$\beta$-CD-TEA has not shown any significant difference in the appearance, $\mathrm{pH}$, floating lag time, viscosity and in vitro drug release characteristics after 3 months of storage (Table-6), which clearly indicates the stability of the optimized buoyant in situ gel.

\section{Conclusion}

Solubility and dissolution rate of meloxicam were successfully increased by preparing its ternary complex with $\beta$ cyclodextrin and triethanolamine and was formulated as buoyant in situ gel. The optimized buoyant in situ gel of meloxicam- $\beta$-cyclodextrin-triethanolamine ternary complex demonstrated a desired gelling and floating property with prolonged and almost complete drug release $(92 \%)$ in an acidic medium ( $\mathrm{pH}$ 1.2). Improved anti-inflammatory activity of the

TABLE-5

ANTI-INFLAMMATORY ACTIVITY OF OPTIMIZED BUOYANT in situ GELS OF MLX- $\beta$-CD-TEA TERNARY COMPLEX

\begin{tabular}{|c|c|c|c|c|c|c|c|c|c|}
\hline \multirow[b]{2}{*}{ Group } & \multirow[b]{2}{*}{ Treatment } & \multirow{2}{*}{$\begin{array}{l}\text { Initial paw } \\
\text { volume }\end{array}$} & \multicolumn{6}{|c|}{ Paw volume $(\mathrm{mL})$} & \multirow{2}{*}{$\begin{array}{l}\text { Edema } \\
\text { inhibition } \\
\text { at } 6^{\text {th }} \mathrm{h} \\
(\%)\end{array}$} \\
\hline & & & $1 \mathrm{~h}$ & $2 \mathrm{~h}$ & $3 \mathrm{~h}$ & $4 \mathrm{~h}$ & $5 \mathrm{~h}$ & $6 \mathrm{~h}$ & \\
\hline I & Control & $1.17 \pm 0.06$ & $1.22 \pm 0.02$ & $1.47 \pm 0.07$ & $1.65 \pm 0.07$ & $1.67 \pm 0.02$ & $1.92 \pm 0.04$ & $2.18 \pm 0.06$ & - \\
\hline II & Standard & $1.07 \pm 0.09$ & $1.18 \pm 0.04$ & $1.30 \pm 0.03 *$ & $1.39 \pm 0.05^{*}$ & $1.42 \pm 0.01 *$ & $1.48 \pm 0.05^{*}$ & $1.57 \pm 0.01 *$ & 59.37 \\
\hline III & Optimized formulation & $1.04 \pm 0.02$ & $1.17 \pm 0.05$ & $1.20 \pm 0.01 *$ & $1.19 \pm 0.02 *$ & $1.32 \pm 0.06^{*}$ & $1.35 \pm 0.03 *$ & $1.32 \pm 0.04 *$ & 84.38 \\
\hline
\end{tabular}

Values are presented as the mean \pm SEM, $\mathrm{n}=6$ in each group; One-way ANOVA followed by multiple Tukey's comparison test. *p $<0.05$, as compared to the control group. ANOVA = analysis of variance; $\mathrm{SEM}=$ standard error of the mean 
TABLE-6

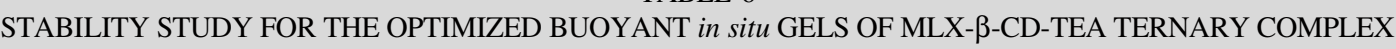

\begin{tabular}{|c|c|c|c|c|c|c|}
\hline Months & Clarity & Colour & $\mathrm{pH}$ & $\begin{array}{c}\text { Floating lag } \\
\text { time (min) }\end{array}$ & Viscosity (cps) & $\begin{array}{c}\text { Cumulative drug } \\
\text { release at } 6^{\text {th }} \mathrm{h}(\%)\end{array}$ \\
\hline 0 & Clear & Pale yellow & $6.93 \pm 0.057$ & $0.70 \pm 0.10$ & $200 \pm 1.00$ & $92.30 \pm 0.22$ \\
\hline 1 & Clear & Pale yellow & $7.00 \pm 0.100$ & $0.83 \pm 0.15$ & $205 \pm 1.73$ & $91.67 \pm 0.39$ \\
\hline 2 & Clear & Pale yellow & $7.06 \pm 0.152$ & $0.93 \pm 0.25$ & $206 \pm 2.08$ & $92.76 \pm 0.27$ \\
\hline 3 & Clear & Pale yellow & $7.10 \pm 0.100$ & $1.06 \pm 0.37$ & $204 \pm 3.46$ & $91.83 \pm 0.57$ \\
\hline
\end{tabular}

optimized formulation as compared to the standard could be due to the ameliorated solubility and dissolution of meloxicam in gastric fluid. The formulation was remained stable for over 3 months. Thus, it can be concluded that buoyant in situ gels of meloxicam- $\beta$-cyclodextrin-triethanolamine ternary complex satisfied the pharmaceutical and pharmacodynamic requirements as a novel drug delivery system and hence may be used for the effective oral delivery of meloxicam.

\section{ACKNOWLEDGEMENTS}

This work was supported by Deanship of Scientific research (DSR), University of Dammam, Saudi Arabia under research group project Grant No.: 2014299. The authors thank Dean of Institute for Research and Medical Consultation (IRMC), University of Dammam, Saudi Arabia for providing animal facilities. Sincere thanks are also due to Dean of College of Clinical Pharmacy and Dean of College of Engineering, University of Dammam, Saudi Arabia, for providing necessary laboratory facilities for this research. The authors extended their sincere thanks to Dr. Syed Sarim Imam for his guidance in statistical interpretation of results.

\section{REFERENCES}

1. P. Luger, K. Daneck, W. Engel, G. Trummlitz and K. Wagner, Eur. J. Pharm. Sci., 4, 175 (1996); https://doi.org/10.1016/0928-0987(95)00046-1.

2. J.L. Wallace, Best Pract. Res. Clin. Gastroenterol., 14, 147 (2000); https://doi.org/10.1053/bega.1999.0065.

3. C. Sostres, C.J. Gargello, M.T. Arroyo and A. Lanas, Best Pract. Res. Clin. Gastroenterol., 24, 121 (2010); https://doi.org/10.1016/j.bpg.2009.11.005.

4. S.C. Shih and C.W. Chang, Int. J. Gerontol., 1, 40 (2007); https://doi.org/10.1016/S1873-9598(08)70022-X

5. C.I. Neutel and W.C. Appel, Ann. Epidemiol., 10, 246 (2000); https://doi.org/10.1016/S1047-2797(00)00040-5.

6. R.N. Gursoy and S. Benita, Biomed. Pharmacother, 58, 173 (2004); https://doi.org/10.1016/j.biopha.2004.02.001.

7. R. Challa, A. Ahuja, J. Ali and R.K. Khar, AAPS PharmSciTech, 6, E329 (2005);

https://doi.org/10.1208/pt060243.

8. H. Bera, S. Chekuri, S. Sarkar, S. Kumar, N.B. Muvva, S. Mothe and J. Nadimpalli, J. Mol. Liq., 215, 135 (2016); https://doi.org/10.1016/j.molliq.2015.12.054

9. I.A. Alsarra, M.O. Ahmed, F.K. Alanazi, K.E.H. Eltahir, A.M. Alsheikh and S.H. Neu, Int. J. Med. Sci., 7, 232 (2010); https://doi.org/10.7150/ijms.7.232.

10. J. Barbosa, A. Zoppi, M. Quevedo, P. de Melo, A. de Medeiros, L. Streck, A. de Oliveira, M. Fernandes-Pedrosa, M. Longhi and A. da Silva-Júnior, Int. J. Mol. Sci., 15, 17077 (2014); https://doi.org/10.3390/ijms150917077.

11. F. Sami, B. Philip and K. Pathak, AAPS PharmSciTech, 11, 27 (2010); https://doi.org/10.1208/s12249-009-9350-y.

12. M.M. Maitre, M.R. Longhi and G.G. Granero, Drug Dev. Ind. Pharm., 33, 311 (2007); https://doi.org/10.1080/03639040600901978.

13. E. Redenti, L. Szente and J. Szejtli, J. Pharm. Sci., 90, 979 (2001); https://doi.org/10.1002/jps. 1050.
14. H.S. Gwak, J.S. Choi and H.K. Choi, Int. J. Pharm., 297, 156 (2005); https://doi.org/10.1016/j.ijpharm.2005.03.016.

15. H.K. Han and H.K. Choi, Eur. J. Pharm. Biopharm., 65, 99 (2007); https://doi.org/10.1016/j.ejpb.2006.07.003.

16. N. Rouge, P. Buri and E. Doelker, Int. J. Pharm., 136, 117 (1996); https://doi.org/10.1016/0378-5173(96)85200-8.

17. A.H. El-Kamel, M.S. Sokar, S.S. Al-Gamal and V.F. Naggar, Int. J. Pharm., 220, 13 (2001); https://doi.org/10.1016/S0378-5173(01)00574-9.

18. S. Miyazaki, N. Kawasaki, W. Kubo, K. Endo and D. Attwood, Int. J. Pharm., 220, 161 (2001); https://doi.org/10.1016/S0378-5173(01)00669-X.

19. W. Kubo, S. Miyazaki and D. Attwood, Int. J. Pharm., 258, 55 (2003); https://doi.org/10.1016/S0378-5173(03)00163-7.

20. M. Prabaharan and J.F. Mano, Macromol. Biosci., 6, 991 (2006); https://doi.org/10.1002/mabi.200600164.

21. P.S. Rajinikanth J. Balasubramaniam and B. Mishra, Int. J. Pharm., 335, 114 (2007); https://doi.org/10.1016/j.ijpharm.2006.11.008.

22. B.C. Thanoo, M.C. Sunny and A. Jayakrishnan, J. Pharm. Pharmacol., 45, 21 (1993); https://doi.org/10.1111/j.2042-7158.1993.tb03672.x.

23. M.H. Dehghan and M. Jafar, Iran. J. Pharm. Res., 4, 231 (2006).

24. M. Jafar, M.H.G. Dehghan and A. Sharif, Int. J. Appl. Pharm., 2, 22 (2010).

25. A. Aejaz, M. Jafar, M.H.G. Dehghan and A. Shareef, Int. J. Pharm. Pharm. Sci., 2, 182 (2010).

26. O. Radia, E. Rogalska and G. Moulay-Hassane, Pharm. Dev. Technol., 17, 632 (2012); https://doi.org/10.3109/10837450.2011.565347.

27. H. El-Maradny, S.A. Mortada, O. Kamel and A. Hikal, Acta Pharm., 58, 455 (2008); https://doi.org/10.2478/v10007-008-0029-9.

28. W. Samprasit, P. Akkaramongkolporn, T. Ngawhirunpat, T. Rojanarata, P. Opanasopit, Drug. Dev. Ind. Pharm., 41, 1006 (2015); https://doi.org/10.3109/03639045.2014.922573.

29. S.S. Awasthi, T.G. Kumar, P. Manisha, Y. Preeti and S.S. Kumar, Pak. J. Pharm. Sci., 24, 533 (2011).

30. K. Gowthamarajan, T.G. Kulkarni, G. Venkateswaran, M.K. Samanta and B. Suresh, Indian J. Pharm. Sci., 64, 525 (2002).

31. M. Jafar and S. Ali, Int. Res. J. Pharm., 2, 220 (2011).

32. G.E.P. Box and K.B. Wilson, J. Royal Statist. Soc., Ser. B, 13, 1 (1951).

33. S. Alam, M. Aslam, A. Khan, S.S. Imam, M. Aqil, Y. Sultana and A. Ali, Drug Deliv., 23, 601 (2016); https://doi.org/10.3109/10717544.2014.923958.

34. T. Higuchi and K.A. Connors, Adv. Anal. Chem. Instrum., 4, 117 (1965).

35. D. Wang, H. Li, J. Gu, T. Guo, S. Yang, Z. Guo, X. Zhang, W. Zhu and J. Zhang, J. Pharm. Biomed. Anal., 83, 141 (2013); https://doi.org/10.1016/j.jpba.2013.05.001.

36. K.M. Lokamatha, A. Bharati, S.M.S. Kumar and N.R. Rao, Int. J. Pharm. Pharm. Sci., 2, 169 (2010).

37. A.A. Jamdhade, R.S. Shendge and V. V. Pande, Int. J. Drug Deliv., 6, 230 (2014).

38. A. Sharma, J. Sharma, R. Kaur and V. Saini, BioMed. Res. Int., Article ID 876182 (2014); https://doi.org/10.1155/2014/876182.

39. P.S. Rajinikanth and B. Mishra, Chem. Pharm. Bull. (Tokyo), 57, 1068 (2009); https://doi.org/10.1248/cpb.57.1068.

40. C.A. Winter, E.A. Risley and R.H. Silber, J. Pharmacol. Exp. Ther., 162, 196 (1968).

41. P. Pandya, N.K. Pandey, S.K. Singh and M. Kumar, J. Appl. Pharm. Sci., 5, 88 (2015); https://doi.org/10.7324/JAPS.2015.50615.

42. P. Costa and J.M. Sousa Lobo, Eur. J. Pharm Sci., 13, 123 (2001); https://doi.org/10.1016/S0928-0987(01)00095-1. 